\title{
An overview of JET edge modelling activities
}

Coster, D.P. ${ }^{\mathrm{a}}$, Bonnin, X. ${ }^{\mathrm{b}}$, Corrigan, $\mathrm{G}^{\mathrm{c}}$, Dejarnac, R. ${ }^{\mathrm{d}}$, Fenstermacher, M. ${ }^{\mathrm{e}}$ Fundamenski, W. ${ }^{\mathrm{c}}$, Geier, A. ${ }^{\mathrm{a}}$, Hogan, $\mathrm{J}^{\mathrm{f}}{ }^{\mathrm{T}}$, Kallenbach, A. ${ }^{\mathrm{a}}$, Kirschner, A. ${ }^{\mathrm{g}}$, Krieger, K. ${ }^{\text {a }}$, Loarte, A. ${ }^{\text {h }}$, Matthews, G. ${ }^{\mathrm{c}}$, Pitts, R.A. ${ }^{\mathrm{i}}$, Porter, G. ${ }^{\mathrm{j}}$, Pugno, R. ${ }^{\mathrm{a}}$, Reiser, D. ${ }^{\mathrm{g}}$, Reiter, D. ${ }^{\mathrm{g}}$, Sipila, S. ${ }^{\mathrm{k}}$, Spence, J. ${ }^{\mathrm{c}}$, Stangeby, P.C. ${ }^{\mathrm{l}}$, Tsitrone, E. ${ }^{\mathrm{d}}$, Tskhakaya, D. ${ }^{\mathrm{m}}$, Wischmeier, M. ${ }^{\mathrm{i}}$ and contributors to the EFDA-JET work programme.

${ }^{a}$ Max-Planck-Institut für Plasmaphysik, EURATOM Association, Garching, Germany

${ }^{\mathrm{b}}$ Max-Planck-Institut für Plasmaphysik, EURATOM Association, Greifswald, Germany

${ }^{\mathrm{c}}$ Euratom/UKAEA Fusion Association, Culham Science Centre, Abingdon, UK

d Association Euratom-CEA, DRFC, CE Cadarache, France

e General Atomics, San Diego, USA

${ }^{\mathrm{f}}$ Oak Ridge National Laboratory, Oak Ridge, USA

${ }^{g}$ Institut für Plasmaphysik, FZ Jülich, EURATOM Association, Jülich, Germany

${ }^{\mathrm{h}}$ European Fusion Development Agreement, Close Support Unit - Garching, Germany

${ }^{\mathrm{i}}$ CRPP, Association EURATOM-Confédération Suisse, EPFL, Lausanne, Switzerland

${ }^{\mathrm{j}} L L N L$, Livermore, USA

${ }^{\mathrm{k}}$ Helsinki University of Technology, Association Euratom-Tekes, Finland

${ }^{1}$ University of Toronto Institute for Aerospace Studies, Toronto, Canada

${ }^{\mathrm{m}}$ Department of Theoretical Physics, University of Innsbruck, Innsbruck, Austria

\begin{abstract}
A number of codes are in use at JET to model the edge plasma. The range of edge codes is described as is the range of physics issues being explored by these codes. The balance between focussed modelling (that looking at particular physics effects) and integrated modelling (attempting to combine codes or encapsulate the physics from some codes into other codes) is examined.
\end{abstract}

\section{Introduction}

An effort is underway to model various aspects of JET edge physics using a number of fluid and kinetic treatments. Amongst the physics issues being addressed are: the determination (and scaling) of the anomalous radial heat (and particle) transport in the edge; the role of various processes in the erosion, transport and deposition of carbon; the observation of a narrow, high heat-flux feature on the outer target plate in low density, high power discharges; pumping and compression of deuterium, helium and other gases; the differences between majority $\mathrm{D}$ discharges and majority $\mathrm{He}$; and issues related to a divertor upgrade (JET-EP). Amongst the tools in use are: ASCOT[1] (a Monte Carlo guiding-centre code); B2-Eirene[2-6] (a coupled 2d fluid plasma, Monte-Carlo neutrals code); DIVIMP (a Monte-Carlo trace impurity code); EDGE2D-NIMBUS[7] (a coupled 2d fluid plasma, Monte-Carlo neutrals code); UEDGE[8] (a fluid plasma code); OSM2/Eirene (a coupled 
multi-1d fluid plasma, Monte-Carlo neutrals code); ERO-JET[9] (a 3D Monte-Carlo, plasmawall-interaction and impurity transport code).

\begin{tabular}{|c|c|c|c|}
\hline & $\begin{array}{l}\text { EDGE2D- } \\
\text { NIM- } \\
\text { BUS }\end{array}$ & $\begin{array}{l}\text { SOLPS5.0 } \\
\text { B2- } \\
\text { EIRENE }\end{array}$ & UEDGE \\
\hline plasma & fluid & fluid & fluid \\
\hline neutrals & $\begin{array}{l}\text { Monte- } \\
\text { Carlo }\end{array}$ & $\begin{array}{l}\text { fluid or } \\
\text { Monte- } \\
\text { Carlo }\end{array}$ & fluid $^{1}$ \\
\hline impurities & yes & yes & yes \\
\hline self-consistent & yes & yes & yes \\
\hline drifts & yes & yes & yes \\
\hline $\begin{array}{l}\text { numerical } \\
\text { stencil }\end{array}$ & $9-\mathrm{pt}$ & $5-\mathrm{pt}^{2}$ & $9-\mathrm{pt}$ \\
\hline $\begin{array}{l}\text { actively } \\
\text { developed }\end{array}$ & no & yes & yes \\
\hline $\begin{array}{l}\text { easily } \\
\text { applicable to a } \\
\text { variety of } \\
\text { devices }\end{array}$ & no & yes & yes \\
\hline $\begin{array}{l}\text { coupled to the } \\
\text { JET } \\
\text { diagnostics }\end{array}$ & yes & $\begin{array}{l}\text { in } \\
\text { progress }\end{array}$ & no \\
\hline $\begin{array}{l}\text { coupled to a } \\
\text { core transport } \\
\text { code }\end{array}$ & $\begin{array}{l}\text { Jetto } \\
\text { (COCO- } \\
\text { NUT) }\end{array}$ & $\begin{array}{l}\text { can } \\
\text { extend } \\
\text { grid to } \\
\text { centre }^{3}\end{array}$ & CORSICA \\
\hline
\end{tabular}

A comparison of the the three self-consistent 2-D edge codes that have been used to simulate JET shots.

The tools range in speed (from a few minutes to weeks of CPU time), the physics addressed (self-consistent plasma; impurities or kinetic ions on a given plasma background) and the geometry used $(1 \mathrm{~d}, 2 \mathrm{~d}$ or $3 \mathrm{~d})$. The goal is to learn more from the ensemble of applied codes than what could be learnt from any particular code. OSM2/Eirene is used to analyse a large number of shots using target Langmuir probe measurements. A more limited number of shots is then analysed with the plasma fluid/kinetic neu-

\begin{tabular}{|c|c|c|c|}
\hline & DIVIMP & $\begin{array}{l}\text { ERO- } \\
\text { JET }\end{array}$ & ASCOT \\
\hline $\begin{array}{l}\text { majority or } \\
\text { impurity }\end{array}$ & impurity & impurity & majority \\
\hline $2 d$ or $3 d$ & $2 d$ & $3 d$ & $3 d$ \\
\hline drifts & No & $\begin{array}{l}\text { partial } \\
(\mathrm{ExB})\end{array}$ & Yes \\
\hline $\begin{array}{l}\text { methane } \\
\text { physics }\end{array}$ & $? ? ?$ & Yes & $\mathrm{N} / \mathrm{A}$ \\
\hline $\begin{array}{l}\text { compu- } \\
\text { tational } \\
\text { expense }\end{array}$ & small & large & 2 days ${ }^{1}$ \\
\hline
\end{tabular}

Table 2

A comparison of the three Monte-Carlo plasma codes that have been used to simulate JET shots.

trals codes (B2-Eirene and EDGE2D-NIMBUS) and the fluid plasma code (UEDGE) [10,11], and a more comprehensive set of experimental diagnostics are used to compare with the code results, which have models for the production, transport and deposition of impurities. Kinetic effects arising from ion orbit loss[12,13] are not included in the plasma fluid codes, but the fluid codes provide the necessary plasma background for the plasma kinetic codes (such as ASCOT), which however are CPU intensive codes and so can only be used to examine a subset of shots. The inclusion of such effects seems to be important in explaining peaked power deposition profiles seen at JET in low density, high power operation, a feature whose mechanism we need to understand because of its possible large implications for the operation of future reactor scale machines. An additional effect, currently not well reproduced by the $2 \mathrm{~d}$ fluid plasma codes, is the asymmetry observed in JET of $\mathrm{C}$ deposition, with most of the deposited $\mathrm{C}$ found near the inner divertor. This, too, is a feature of the plasma that has crucial implications for the choice of materials for a future device. 3d, Monte-Carlo plasma codes are being used to supplement the $2 \mathrm{~d}$ fluid plasma codes to explore the mechanisms of $\mathrm{C}$ erosion, transport and deposition, and the role of the complicated C chemistry[14]. Additional effects can be expected from ExB and diamagnetic drifts in the plasma, and runs with the plasma codes which include these effects will provide ad- 
ditional insight $[10,15]$.

\section{Some physics issues being examined}

In an effort to improve the data gathered by the edge diagnostics, two Diagnostic Optimised Configurations (DOC) have been devised one which is optimised for the measurement of pedestal and SOL temperature and density gradients by the edge LIDAR, and the second for the measurements of quantities at the target plates (e.g. thermography). Simulations with the same parameters, but with the different geometries show similar upstream profiles (figure 1) but different target profiles (figure 2) caused by the change from vertical target to horizontal target. The extent to which the DOC-U and DOC-L discharges show experimental differences upstream is indicative that the assumption of similar transport used in the modelling is not valid.

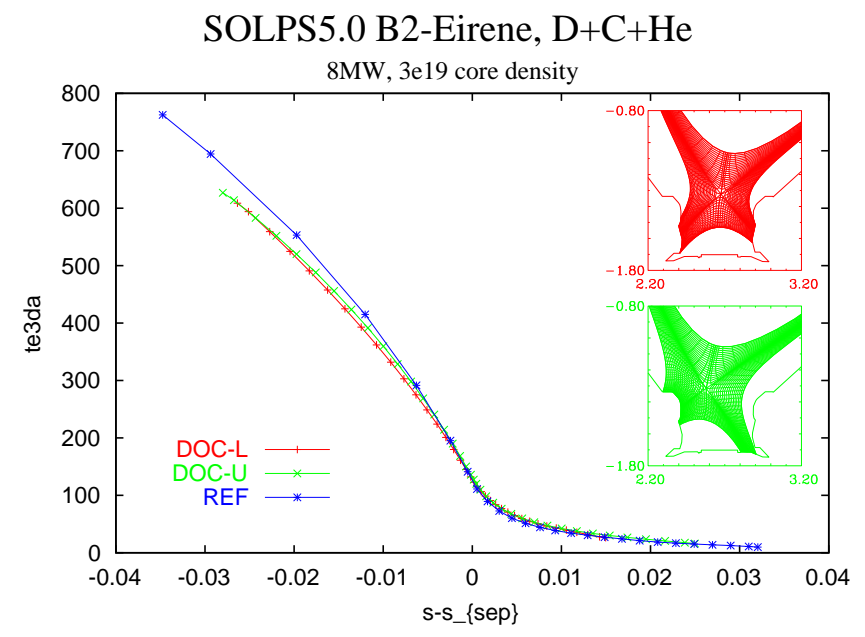

Fig. 1. Upstream electron temperature profiles from a SOLPS5.0 B2-Eirene simulation. Inset are zooms of the divertor region of the DOC-L and DOC-U grids. (The reference grid is shown as an inset in figure 2.)

Using the same plasma parameters, but changing from D to He produces large differences in the simulations. Figure 3 shows profile of the outer target electron temperature for cases with varying He concentration from simulations with the DOC-U configuration.

Experimentally, the pattern of tritium and deuterium co-deposition seems to be asymmetric

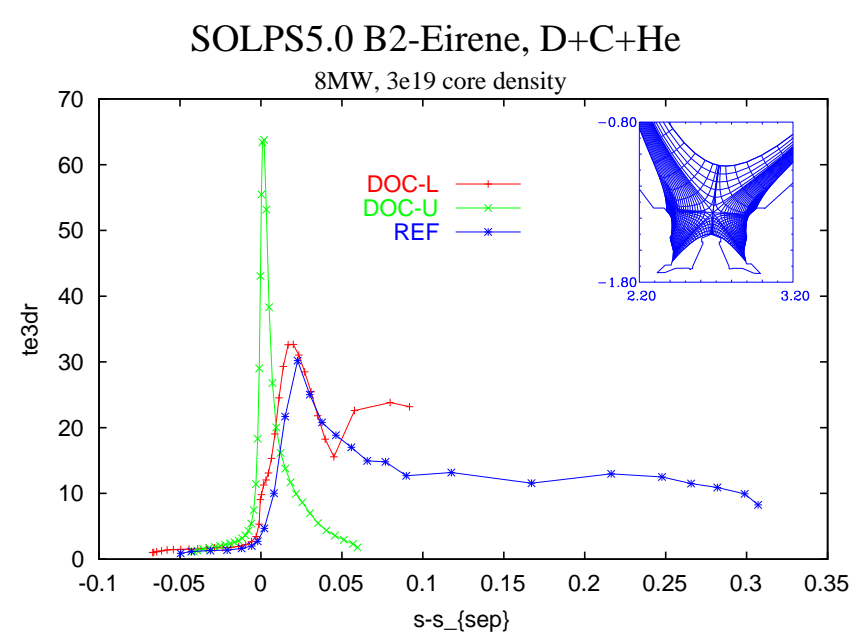

Fig. 2. Outer target electron temperature profiles from a SOLPS5.0 B2-Eirene simulation. Inset is a zoom of the divertor region of the reference grid. (The DOC-L and DOC-U grids are shown as insets in figure 1.)

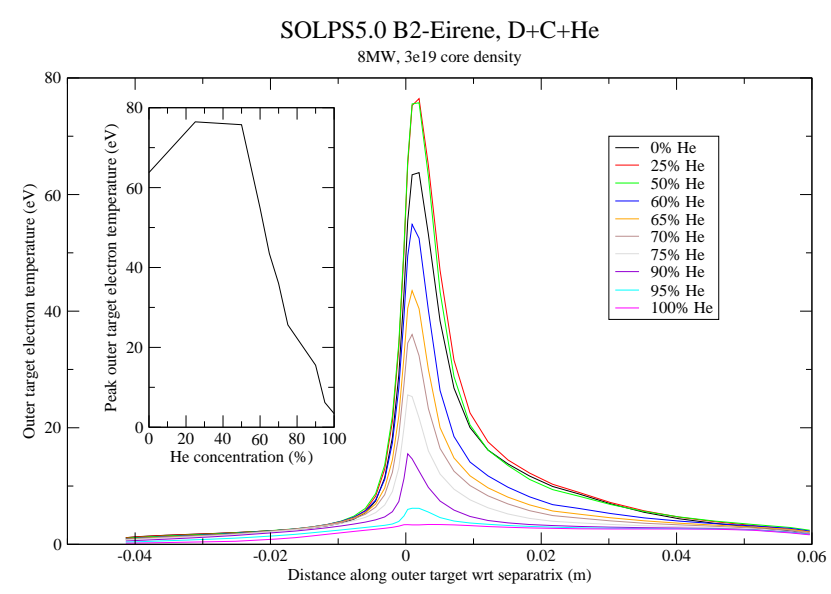

Fig. 3. Electron temperature at the outer target for a number of code runs with varying helium concentration. Inset is the peak outer target electron temperature as a function of the helium concentration. $8 \mathrm{MW}$ simulations of the JET DOC-U configuration.

between the inner and outer divertor with significantly more deposition occurring around the inner target. Detailed modelling of this is in progress with ERO-JET, but some initial impressions can also be obtained by looking at a number of SOLPS runs. Figure 4 shows the ratio of $\mathrm{C}$ ion flux to $\mathrm{D}$ ion flux to the inner and outer divertors for a range of simulations (core density variations, pumping variations, transport variations), and for most of the cases there is not much difference between the inner and outer divertors. For one particular case, though, the chemical sputtering was artificially increased just for the inner target (mocking up to some 
extent the possibility of soft amorphous hydrocarbon films in that area), and this, not surprisingly, did produce the desired affect - a large asymmetry in the $\mathrm{C}$ fluxes to the two divertors.

Fig. 4. Ratio of $\mathrm{C}$ ion fluxes to the $\mathrm{D}$ ion flux for the inner and outer targets versus the sum of the $\mathrm{D}$ ion flux to both targets. The two pairs of selected points correspond to a case where the chemical sputtering coefficient was artificially increased from $1 \%$ (the two points in the band) to $10 \%$ (which has the point for the inner target raised well above the band of points). There are also some interesting points with large in/out asymmetries between the C-to-D flux ratios at low $\mathrm{D}+$ flux values: these plasma are dominated by strong volume recombination, particularly in the inner divertor.

ExB and diamagnetic drifts would also be expected to play a role, and efforts are underway to examine the effects of drifts on the $\mathrm{C}$ transport within the plasma.

\section{Focussed modelling versus integrated modelling}

As can be seen from the extensive list of codes in use for edge modelling on JET, a large effort is underway to understand the various pieces of the physics that make the edge such a complex system. At some point, though, one is forced to address the balance between the separate, focussed modelling, and an effort to integrate the pieces together.

While trying to understand the importance of each piece of the physics, the focussed model is probably the fastest way to go. Once a piece is well understood, though, its impact on other pieces also needs to be examined, and for this a more integrated approach is necessary. This is particularly important if synergetic effects come into play: as an example, if the production of an amorphous hydrocarbon surface increases the $\mathrm{C}$ content of the local plasma, which in turn would decrease the local temperature, which might further favour the development of the amorphous hydrocarbon film. The converse might also occur: the presence of an energetic ion minority might change the plasma conditions close to the target which might reduce the development of an amorphous hydrocarbon film.

In order to incorporate these effects, some sort of integrated modelling might become necessary. In fact, the edge codes like B2-Eirene and EDGE2D-NIMBUS are already a step on this path, and already incorporate the two ways that the integration can occur: the direct coupling of two codes (the fluid plasma codes to the Monte-Carlo neutrals codes) as well as a more indirect coupling via tables or functions (giving sputtering rates, reflection coefficients, atomic physics rates, etc.). The incorporation of the new physics pieces discovered by the focussed efforts, would then be incorporated into the existing codes (fairly easily), or perhaps into new codes (a major piece of work).

At JET, similar work has looked at coupling the edge to the core (COCONUT), but the results of the focussed studies has suggested the importance of incorporating more physics into the edge codes. Amongst the physics issues that might need to be included are (1) the determination of transport coefficients (perhaps by coupling to turbulence codes); (2) kinetic effects: (a) the effect of fast electrons/ions on the plasma, particularly during ELMs, (b) ion orbit losses; (3) Impurities: (a) methane (and higher hydrocarbon) breakup, (b) the nature of the deposited hydrocarbon layer in regions of net deposition; (4) neutral-neutral collisions; (5) photon transport and its effects on the ionisation balance; (6) 3-D effects

The cost of including these additional contributions is not insignificant: (1) the codes are still not as robust as one would like when handling drift terms, and the addition might make things worse, (2) there is a large disparity in the various time-scales which will need to be addressed.

The gains, too, would not be insignificant: the possibility of making quantitative, reliable predictions of (1) erosion and re-deposition, (2) heat loads to the targets, and (3) behaviour during ELMs, amongst others. 


\section{Conclusion}

It is clear that, as yet, no one code provides all of the answers for what is going on in the edge plasma. However, by combining the various available codes, and leveraging their various individual strengths, we are moving closer to a better understanding of the important area of edge and divertor physics.

\section{References}

[1] J. Heikkinen, T. Kiviniemi, T. Kurki-Suonio, A. Peeters, S. Sipilä, Particle simulation of the neoclassical plasmas, Hournal of Computational Physics 173 (2001) 527-548.

[2] B. J. Braams, Computational studies in tokamak equilibrium and transport, Ph.D. thesis, Rijksuniversiteit, Utrecht, Nederland. (1986).

[3] D. Reiter, Progress in two-dimensional plasma edge modelling, Journal of Nuclear Materials 196-198 (1992) 80-89.

[4] D. Reiter, P. Boerner, B. Kueppers, M. Baelmans, G. Maddison, Final report on net contract 428/90-8/fu-d, Tech. Rep. 428/90-8/FU-D, NET, EURATOM (1990).

[5] R. Schneider, D. Coster, B. Braams, P. Xantopoulos, V. Rozhansky,

S. Voskoboynikov, L. Kovaltsova, H. Hürbaumer, B2-solps5.0: SOL transport code with drifts and currents, Contrib. Plasma Phys. 40 (3-4) (2000) 328-333.

[6] V. Rozhansky, S. Voskoboynikov, E. Kaveeva, D. Coster, R. Schneider, Simulation of tokamak edge plasma including self-consistent electric fields, Nuclear Fusion 41 (4) (2001) 387-401.

[7] R. Simonini, G. Corrigan, G. Radford, J. Spence, A. Taroni, Models and numerics in the multi-fluid 2-d edge plasma code edge2d/u, Contrib. Plasma Physics 34 (2/3) (1994) 368-373, 4th Workshop on Plasma Edge Theory, October 1993, Varenna, Italy.

[8] T. Rognlien, P. Brown, R. Campbell, T. Kaiser, D. Knoll, P. McHugh, G. Porter,
M. Rensink, G. Smith, 2-d fluid transport simulations of gaseous/radiative divertors, Contrib. Plasma Physics 34 (2/3) (1994) 362-367, 4th Workshop on Plasma Edge Theory, October 1993, Varenna, Italy.

[9] A. Kirschner, V. Philipps, J. Winter, U. Kögler, Simulation of the plasma-wall interaction in a tokamak with the monte carlo code ero-textor, Nuclear Fusion 40 (5) (2000) 989-1001.

[10] G. Porter, T. Rognlien, M. Rensink, H. Takenaga, N. Asakura, A. Loarte, G. Matthews, , contributors to the EFDA-JET workprogramme, Simulation of the effect of plasma flows in diii-d, jet, and jt-60u, this conference.

[11] M. Fenstermacher, S. Erents, K. Lawson, G. Matthews, G. McCracken, V. Philipps, R. Pitts, M. Stamp, C. to the EFDA-JET Workprogramme, Comparison of carbon and main ion radiation profiles in matched helium and deuterium plasmas in jet, this conference.

[12] W. Fundamenski, S. Sipila, T. Kiviniemi, T. Kurki-Suonio, G. Matthews, V. Riccardo, contributors to the EFDA-JET work programme, Narrow power profiles seen at jet and their relation to ion orbit losses, this conference.

[13] G. Matthews, G. Corrigan, S. Erents, W. Fundamenski, T. Kurki-Sounio, S. Sipila, J. Spence, contributors to the EFDA-JET workprogramme, The effect of ion orbit losses on jet edge plasma simulations, this conference.

[14] A. Kirschner, J. Brooks, V. Philipps, P. Wienhold, A. Pospieszczyk, R. Janev, Modelling of chemical erosion and redeposition of methane and higher hydrocarbons in fusion devices, this conference.

[15] V. Rozhansky, E. Kaveeva, S. Voskoboynikov, A. Beckheit, D. Coster, X. Bonnin, R. Schneider, Impact of ExB drifts on the distribution of impurities in the tokamak plasma edge, this conference. 